\title{
LISREL ve AMOS Programları Kullanılarak Gerçekleştirilen Yapısal Eşitlik Modeli (YEM) Analizlerine İliş̧kin Sonuçların Karşılaștırılması ${ }^{*}$
}

\section{Comparing the Analysis Results of the Structural Equation Models (SEM) Conducted Using LISREL and AMOS}

\author{
Mustafa İLHAN ${ }^{* *} \quad$ Bayram ÇETIN ${ }^{* * *}$
}

$\ddot{O} z$

$\mathrm{Bu}$ araştırmada, yapısal eşitlik modeli çatısı altında yer alan ve uyum düzeyleri açısından farklılık gösteren yol analizi, Doğrulayıcı Faktör Analizi (DFA) ile yapısal model için LISREL ve AMOS programlarından elde edilen analiz çıktılarının karşılaştırılması amaçlanmıştır. Dolayısıyla, araştırmada evren ve örneklem tayinine ihtiyaç duyulmamıştır. Araştırma; her bir modeli yansıtan bir veri dosyası olmak üzere üç ayrı veri seti üzerinden yürütülmüştür. Yol analizinde kullanılan veri seti düşük uyum gösteren bir model; DFA'da kullanılan veri seti kabul edilebilir uyum gösteren bir model ve yapısal modelde kullanılan veri seti mükemmel uyum gösteren bir model olarak belirlenmiştir. Bu şekildeki bir yaklaşımın, LISREL ve AMOS programlarından elde edilen uyum indeksleri arasındaki farkın analiz edilen modelin uyum düzeyinden etkilenip etkilenmediği sorusunu yanıtlamayı olanaklı hale getireceği düşünülmüştür. Analiz çıktıları incelendiğinde; model uyumunun mükemmel olduğu veri setinde LISREL ve AMOS programından elde edilen uyum indekslerinin büyük ölçüde tutarlı olduğu belirlenmiş̧tir. Model ile veri seti arasındaki uyumunun düşük olduğu modelde ise, iki programda rapor edilen uyum indeksleri arasındaki farkın daha fazla olduğu saptanmıştır. Bu farkın, özellikle, $\chi^{2} / \mathrm{sd}$, NNFI ve RFI indeksleri için belirgin olduğu sonucuna ulaşılmıştır. Bu sonuçlar; LISREL ve AMOS programlarında rapor edilen uyum indeksleri arasındaki farkın modelin uyum düzeyinden etkilendiğini ortaya koymaktadır.

Anahtar Kelimeler: Yapısal eşitlik modeli, uyum indeksleri, LISREL, AMOS

\begin{abstract}
This study aimed to compare the analysis results obtained through LISREL and AMOS for the models of path analysis, Confirmatory Factor Analysis (CFA) and structural regression, which are within structural equation model and differ in levels of fit. Therefore, population and sample were not needed in the study. The study was conducted on three different data sets that reflected the models through a data file. The data set used in the path analysis was determined to reflect a low fit model, while the one used in CFA was determined to reflect an acceptable fit model. However, the data set used in the structural model reflected a good fit. In this way, it was believed that it would be possible to find an answer to the question of whether the differences in the fit indexes obtained through LISREL and AMOS were affected by the fit level of the model analyzed. The analysis results indicated that the fit indexes obtained through LISREL and AMOS were substantially similar in the data set that reflected a good fit. The differences in the fit indexes obtained through these two software packages were found to be larger in the model that reflected a low fit between the model and the data set. It was also found that this difference was remarkable, particularly in $\chi^{2} / s d$, NNFI and RFI indexes. These results indicate that the differences in the fit indexes reported by LISREL and AMOS are affected by the fit level of the model.
\end{abstract}

Key Words: Structural equation model, fit indices, LISREL, AMOS

\footnotetext{
* IV. Eğitimde ve Psikolojide Ölçme ve Değerlendirme Kongresi’nde sözlü bildiri olarak sunulmuştur.

Arş̧. Gör., Dicle Üniversitesi, Ziya Gökalp Eğitim Fakültesi, İlköğretim Bölümü, Diyarbakır-Türkiye. e-posta: mustafailhan21@gmail.com

Doç. Dr. Gaziantep Üniversitesi, Gaziantep Eğitim Fakültesi, Eğitim Bilimleri Bölümü, Gaziantep-Türkiye. e-posta: $\underline{\text { bcetin27@gmail.com }}$
} 


\section{GİRIȘ}

Yapısal eşitlik modellemesi (YEM); sosyal bilimler, davranış bilimleri, eğitim bilimleri, ekonomi ve tıbbi bilimler gibi birçok farklı alanda (Bentler \& Yuan, 1999; Cheung \& Renswold, 2002; Raykov \& Marcoulides, 2006) belirli bir kuramsal temele dayalı olarak (Jöreskog \& Sörbom, 1993), gözlenen ve örtük değişkenler arasındaki ilişkileri test etmek amacıyla bilim adamları tarafindan sıklıkla kullanılmaktadır (Hoyle, 1995; Leech, Barrett \& Morgan, 2005). YEM'in, birçok farklı alanda yoğun olarak kullanılması (Hershberger, 2003), geleneksel yöntemlerden farklı olarak gözlenen değişkenlere ait ölçüm hatalarını dikkate almasından kaynaklanmaktadır (Schumacker \& Lomax, 2004; Stevens, 2009). YEM'in bilimsel araştırmalarda yaygın biçimde kullanılmasının bir diğer nedeni, hem bir değişkenden diğerine giden doğrudan etkileri, hem de iki değişken arasında, aracı bir değişkenin etkisiyle oluşan dolaylı etkileri içeren çok değişkenli modelleri geliştirme, tahmin ve test etmeye olanak tanımasıdır. Söz konusu çok değişkenli modelleri test etmenin matematiksel karmaşıklığı, YEM uygulamalarında bilgisayar yazılımlarını kullanmayı bir zorunluluk haline getirmektedir (Raykov \& Marcoulides, 2006).

Günümüze kadar, YEM analizlerini yürütmek için çeşitli bilgisayar programları kullanılmıştır (Boker vd., 2011; Kline, 2011; Lei \& Wu, 2007). LISCOMP (Muthen, 1987), LINCS (Schoenberg \& Arminger, 1988) COSAN (Fraser \& McDonald, 1988), SEpath (Steiger, 1994), MECOSA 3 (Arminger, 1997), Analysis of Moment Structures (AMOS) (Arbuckle \& Wothke, 1999), Linear Structural Relationships (LISREL) (Jöreskog \& Sörbom, 2000), RAMONA (Browne \& Mels, 2000), EQS (Bentler, 2004), Mplus (Muthén \& Muthén, 2004), Mx (Neale, Boker, Xie, \& Maes, 2004) ve CALIS (PROC CALIS, 1989) programları YEM analizlerini gerçekleştirmek için kullanılan yazılımlar arasında yer almaktadır. Alanyazında, bu programlar arasında benzerlikler kadar farklılıkların da olduğu (Davey \& Savla, 2010) ve her programın bir takım güçlü ve zayıf yönlerinin bulunduğu ifade edilmektedir (Hox \& Bechger, 1998; Reisinger \& Turner, 1999). Ancak literatürde, bu programlar arasında ne tür farklılıkların olduğunu ortaya koyan yeterince araştırma bulunmadığı görülmektedir. Özellikle modelleme sürecindeki en tartışmalı ve kritik işlemi temsil eden uyum indeksleri (Hooper, Coughlan \& Mullen, 2008) açısından, farklı bilgisayar programları kullanılarak gerçekleştirilen YEM analizlerinin birbiriyle ne derece tutarlı sonuçlar verdiğini belirlemeye yönelik sınırlı sayıda araştırma (Albright \& Park, 2008; Byrne, 2001; Clayton \& Pett, 2008, Ferrer, Hamagami \& McArdle, 2004; Hox, 1995) bulunmaktadır. Bu araştırmaları özetlemek gerekirse; Hox (1995) tarafından yapılan çalışmada, AMOS, EQS ve LISREL programları kullanılarak yapısal model analizi yürütülmüş ve elde edilen sonuçların birbirleri ile ne derece uyumlu olduğu araştırılmıştır. Byrne (2001) tarafından yapılan çalışmada doğrulayıcı faktör analizi (DFA) modelini içeren bir veri dosyası üzerinden AMOS, EQS ve LISREL paket programları ile gerçekleştirilen analizlere ilişkin sonuçlar karşılaştırmalı olarak incelenmiştir. Ferrer, Hamagami ve McArdle (2004) tarafindan yapılan çalışmada, Mplus, AMOS ve SAS-NLMIXED programları aracılığıyla örtük değişim modeli analizi gerçekleştirilmiş ve farklı programlardan elde edilen analiz çıktıları arasındaki tutarlılık belirlenmeye çalışılmıştır. Albright ve Park (2008) tarafindan yapılan çalışmada, AMOS, LISREL, Mplus, SAS/STAT ve CALIS paket programları kullanılarak DFA gerçekleştirilmiş ve farklı programlardan elde edilen analiz çıtıları arasındaki tutarlılık incelenmiştir. Clayton ve Pett (2008) tarafindan yapılan çalışmada ise yol analizi modelini yansıtan bir veri seti üzerinden AMOS ve LISREL paket programları karşılaştırılmıştır. YEM analizlerini gerçekleştirmek amacıyla kullanılan bilgisayar programlarının karşılaştırılmasına yönelik bu araştırmaların ortak özelliği; hepsinin tek bir veri seti üzerinden yürütülmüş olmasıdır. Bu durum, farklı 
programlardan elde edilen analiz çıktıları arasındaki tutarlılığın, modelin uyumuna göre değişip değişmediği sorusunun yanıtsız kalmasına neden olmaktadır. Diğer bir deyişle, yüksek ve düşük uyum gösteren modellerde farklı programlardan elde edilen analiz sonuçları arasındaki tutarlığın belirlenebilmesi için uyum düzeyi farklı olan modellerin değişik YEM programları ile incelenmesi ve elde edilen sonuçların karşılaştırılması gerekmektedir. Bu kapsamda araştırmada, farklı uyum düzeylerine sahip olan ve YEM çatısı altında yer alan yol analizi, DFA ve yapısal modele ilişkin farklı bilgisayar programlarından elde edilen analiz çıktılarının karşılaştırılması amaçlanmaktadır. YEM analizlerini gerçekleştirmek üzere geliştirilen programların sayısı oldukça fazla olduğundan, tek bir araştırma ile söz konusu bilgisayar programlarının tümünü ele almak mümkün görünmemektedir. Bu noktadan hareketle araştırma, YEM analizlerini gerçekleştirmek üzere tasarlanan bilgisayar programları arasında araştırmacılar tarafından en fazla tercih edilen, en popüler (Hox \& Bechger, 1998; Reisinger \& Turner, 1999; Rossel, 2012) ve kullanıcı dostu olan LISREL ve AMOS (Albright \& Parker, 2008) paket programları ile sınırlı tutulmuştur. Araştırmanın herhangi bir modifikasyonun uygulanmadığı veri setleri üzerinde yürütülmesi, çalışmaya ilişkin ikinci bir sınırlılık olarak görülebilir.

\section{Kuramsal Çerçeve}

YEM; faktör analizi, kanonik korelasyon ve çoklu regresyon gibi farklı istatistiksel yöntemlerin bir birleşimi olarak tanımlanmaktadır (Hox \& Bechger, 1998; Pallant, 2005; Ullman, 2001). YEM, gözlenen ve gizil değişkenler içermesi ve gizil değişkenlerin gözlenen değişkenler ile tanımlanması yönüyle faktör analizini (Kahn, 2006; Tabachnick \& Fidell, 2007), birçok bağımlı ve bağımsız değişken içermesi yönüyle kanonik korelasyonu ve değişkenler arasındaki nedensel ilişkileri tanımlaması yönüyle regresyon analizini içermektedir (Tabachnick \& Fidell, 2007). Faktör analizi, kanonik korelasyon ve regresyon analizi gibi farklı istatistiksel tekniklerin bir birleşimi olarak ifade edilmesi, YEM'in yol analizi, DFA (ölçüm modeli) ve yapısal model gibi değişik başlıklar altında incelenmesine neden olmaktadır.

\section{Yol Analizi Modelleri}

Yol analizi, yalnızca gözlenen değişkenler üzerinden işlem yapmakta (Raykov \& Marcoulides, 2006) ve nedensel modelleme için çoklu regresyon analizi tekniklerini kullanmaktadır (Bordens \& Abbott, 2011). Yalnızca gözlenen değişkenler üzerinden işlem yapılması nedeniyle, yol analizi bazı araştırmacılar tarafından bir YEM olarak değerlendirilmemektedir. Bununla birlikte; yol analizi, model uyumu ve testi gibi YEM'in diğer türleriyle aynı temel mantıkta çalıştığından ve YEM'in tarihsel gelişimi içersinde önemli bir yere sahip olduğundan YEM'in bir türü olarak ele alınabilmektedir (Raykov \& Marcoulides, 2006). Şekil 1'de bir yol analizi modeli örneği gösterilmiştir.

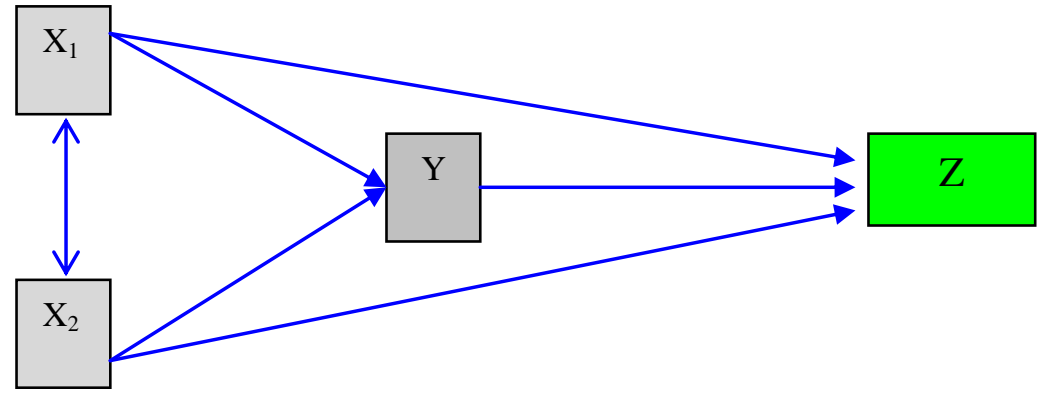

Şekil 1: Yol Analizi Modeli Örneği 


\section{Doğrulayıcı Faktör Analizi (DFA) Modelleri}

Ölçüm modeli olarak da isimlendirilen DFA, gözlenen değişkenler ile bu gözlenen değişkenler aracılığıyla ölçüldügü kabul edilen yapı ya da yapılar arasındaki ilişkileri test etmek için kullanılmaktadır (Wetson \& Gore, 2006). Diğer YEM'lerde olduğu gibi, DFA modelleri de bir kuramsal temelden hareketle gerçekleştirilmekte (Schreiber, Stage, King, Nora \& Barlow, 2006) ve bu yönüyle açımlayıcı faktör analizinden farklılık göstermektedir (Byrne, 2010; Mulaik, 2009). Şekil 2'de iki faktörlü bir ölçek için DFA modeli örneği gösterilmiştir.

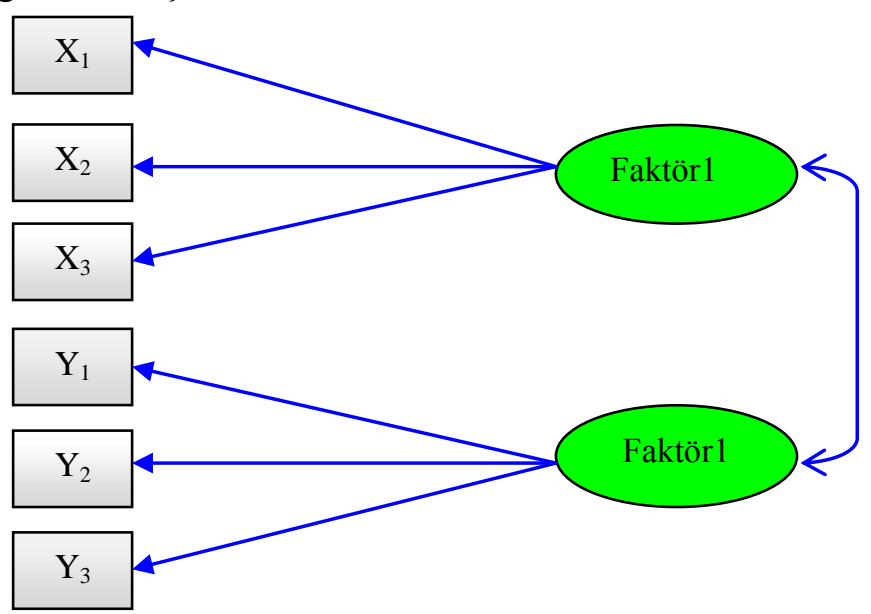

\section{Şekil 2: DFA Modeli Örneği}

\section{Yapisal Model}

Yapısal model DFA'yı andırmaktadır. Ancak DFA'dan farklı olarak, örtük değişkenler arasındaki açıklayıcı ilişkiler de dikkate alınmaktadır (Raykov \& Marcoulides, 2006). Buna göre; yapısal model, örtük değişkenler arasındaki ilişkileri test etmek amacıyla kullanılan bir model olarak tanımlanabilir (Wetson \& Gore, 2006). Şekil 3 'te F1 ve F2 olarak adlandırılan iki örtük değişken arasındaki ilişkiyi gösteren yapısal model örneği sunulmuştur.

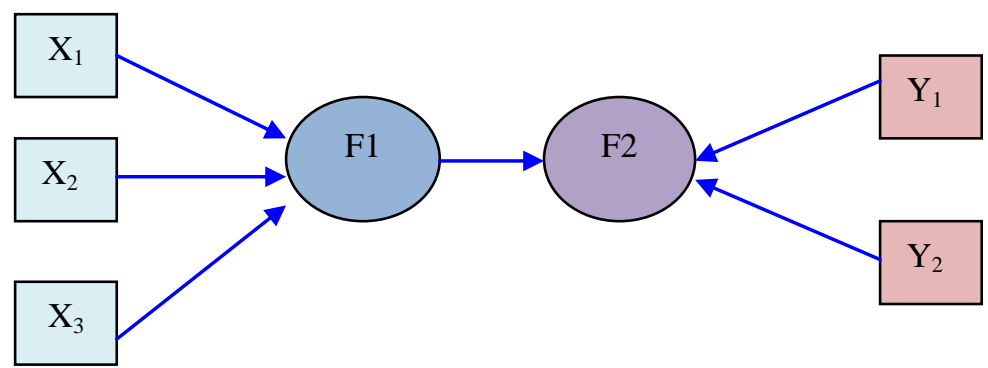

Şekil 3: Yapısal Model Örneği

Yol analizi, DFA ve yapısal modele ilişkin özellikler dikkate alındığında, YEM'de, veri setlerinin içerdiği değişkenler (gözlenen-örtük) ve test edilmek istenen teorik yapıya bağlı olarak farklı modellerin kullanıldığı söylenebilir. Bununla birlikte, söz konusu modellerden hangisi kullanılırsa kullanılsın YEM'in öncelikli amac1; teorik modellerin veri seti tarafindan doğrulanıp doğrulanmadığını ortaya koymaktır (Bayram, 2010). Test edilmek istenen teorik yapının veri seti tarafından doğrulanıp doğrulanmadığını belirlemek için uyum indekslerinden yararlanılmaktadır (Bentler \& Yuan, 1999; Pedhazur, 1997). Model uyumunun testi için kullanılan çok sayıda uyum indeksi bulunmaktadır (Hair, Anderson, 
Tatham \& Black, 1998; Widaman \& Thompson, 2003). YEM analizlerini gerçekleştirmek için kullanılan paket programlarda, bazı benzer uyum iyiliği indeksleri hesaplansa da; birçok da farklı uyum indeksi üretilmektedir (Meydan \& Şeşen, 2011; Reisinger \& Mavondo, 2007). Dolayısıyla model uyumunun değerlendirilmesi, kullanılan paket programa göre değişebilmektedir (Çokluk, Şekercioğlu \& Büyüköztürk, 2012). Bu araştırmada yer verilen AMOS ve LISREL paket programlarında ise, bazı uyum indeksleri farklı isimlerle hesaplanmakta, ancak her iki programda da model uyumunun testinde benzer uyum indeksleri kullanılmaktadır (Brown, 2006).

Hem LISREL hem de AMOS programında, model uyumunu test etmek amaciyla incelenen ilk uyum indeksi Ki Kare $\left(\chi^{2}\right)^{\prime}$ dir. $\chi^{2}$ gözlenen (observed) kovaryans matrisi ile kestirilen kovaryans matrisi arasındaki farkın anlamlılığını test etmektedir (Bagozzi \& Heatherton, 1994). $\chi^{2}$ değerinin anlamlı olmaması gözlenen kovaryans matrisi ile kestirilen kovaryans matrisi arasında anlamlı fark bulunmadığını ve dolayısıyla modelin uyumlu olduğu gösterir (Hair vd., 1998; Tabachnick \& Fidell, 2007). Öte yandan, $\chi^{2}$ değeri örneklem büyüklügüne oldukça duyarlı olduğundan (Bagozzi \& Yi, 1988; Gerbing \& Anderson 1985), büyük örneklemlerle çalışıldığında $\chi^{2}$ değeri çoğunlukla anlamlı çıkmaktadır. Bu nedenle, model uyumunu değerlendirirken, doğrudan $\chi^{2}$ değerinden hareket etmek yerine; $\chi^{2}$ değerinin serbestlik derecesine bölünmesiyle elde edilen değerin esas alınması önerilmektedir (Hoe, 2008; Şimşek, 2007). $\chi^{2}$ 'nin dişında model uyumunu test etmek amacıyla çok sayıda farklı uyum indeksi kullanılmaktadır. Tahmin hatalarının ortalamasının karekökü (Root Mean Square Error of Approximation, RMSEA), iyilik uyum indeksi (Goodness of Fit Index, GFI), düzeltilmiş iyilik uyum indeksi (Adjustment Goodness of Fit Index, AGFI), standartlaştırılmış hata kareleri ortalamasının karekökü (Standardized Root Mean Square Residual, SRMR) karşılaştırmalı uyum indeksi (Comparative Fit Index, CFI), göreli uyum indeksi (Relative Fit Index, RFI), fazlalık uyum indeksi (Incremental Fit Index, IFI), normlaştırılmış uyum indeksi (Normed Fit Index, NFI), LISREL'de normlaştırılmamış uyum indeksi ve AMOS'ta Tucker Lewis Index şeklinde yer alan NNFI-TLI, sıkı normlaştırılmış uyum indeksi (Parsimony Normed Fit Index, PNFI), s1k1 iyilik uyum indeksi (Parsimony Goodness of Fit Index, PGFI), akaike bilgi kriteri (Akaike Information Criteration, AIC), tutarlı akaike bilgi kriteri (Consistent Akaike Information Criteration, CAIC) ve beklenen çarpraz geçerlilik indeksi (Expected Cross Validation Index, ECVI) YEM araştırmalarında model uyumunu değerlendirmek amaciyla kullanılan uyum indeksleri arasında yer almaktadır. Sıralanan uyum indekslerine ilişkin mükemmel ve kabul edilebilir uyum ölçütleri Tablo 1'de sunulmuştur. 
Tablo 1. Yapısal Eşitlik Modeli Araştırmalarında Kullanılan Uyum İndekslerine İlişkin Mükemmel ve Kabul Edilebilir Uyum Ölçütleri

\begin{tabular}{|c|c|c|}
\hline Uyum İndeksleri & Mükemmel Uyum Ölçütleri & Kabul Edilebilir Uyum Ölçütleri \\
\hline${ }^{1} \chi^{2} / s d$ & $0 \leq \chi^{2} / s d \leq 2$ & $2 \leq \chi^{2} / s d \leq 3$ \\
\hline${ }^{2} \mathrm{AGFI}$ & $.90 \leq \mathrm{AGFI} \leq 1.00$ & $.85 \leq \mathrm{AGFI} \leq .90$ \\
\hline${ }^{3} \mathrm{GFI}$ & $.95 \leq \mathrm{GFI} \leq 1.00$ & $.90 \leq \mathrm{GFI} \leq 95$ \\
\hline${ }^{3} \mathrm{CFI}$ & $.95 \leq \mathrm{CFI} \leq 1.00$ & $.90 \leq \mathrm{CFI} \leq .95$ \\
\hline${ }^{3} \mathrm{NFI}$ & $.95 \leq \mathrm{NFI} \leq 1.00$ & $.90 \leq \mathrm{NFI} \leq .95$ \\
\hline${ }^{3} \mathrm{NNFI}$ (TLI) & $.95 \leq \mathrm{NNFI}(\mathrm{TLI}) \leq 1.00$ & $.90 \leq \mathrm{NNFI}(\mathrm{TLI}) \leq .95$ \\
\hline${ }^{3} \mathrm{RFI}$ & $.95 \leq \mathrm{RFI} \leq 1.00$ & $.90 \leq \mathrm{RFI} \leq .95$ \\
\hline${ }^{3}$ IFI & $.95 \leq \mathrm{IFI} \leq 1.00$ & $.90 \leq \mathrm{IFI} \leq .95$ \\
\hline${ }^{4}$ RMSEA & $.00 \leq$ RMSEA $\leq .05$ & $.05 \leq$ RMSEA $\leq .08$ \\
\hline${ }^{4}$ SRMR & $.00 \leq \mathrm{SRMR} \leq .05$ & $.05 \leq \mathrm{SRMR} \leq .10$ \\
\hline${ }^{5} \mathrm{PNFI}$ & $.95 \leq \mathrm{PNFI} \leq 1.00$ & $.50 \leq \mathrm{PNFI} \leq .95$ \\
\hline${ }^{6} \mathrm{PGFI}$ & $.95 \leq \mathrm{PNFI} \leq 1.00$ & $.50 \leq \mathrm{PNFI} \leq .95$ \\
\hline${ }^{7} \mathrm{AIC}$ & \multicolumn{2}{|c|}{ Karşılaştırılan modeller arasında en küçük değere sahip olan model } \\
\hline${ }^{7} \mathrm{CAIC}$ & \multicolumn{2}{|c|}{ Karşılaştırılan modeller arasında en küçük değere sahip olan model } \\
\hline${ }^{7} \mathrm{ECVI}$ & \multicolumn{2}{|c|}{ Karşılaştırılan modeller arasında en küçük değere sahip olan model } \\
\hline
\end{tabular}

${ }^{1}$ (Kline, 2011), ${ }^{2}$ (Schermelleh-Engel \& Moosbrugger, 2003), ${ }^{3}$ (Baumgartner \& Homburg, 1996; Bentler, 1980; Bentler \& Bonett, 1980; Marsh, Hau, Artelt, Baumert \& Peschar, 2006), ${ }^{4}$ (Browne \& Cudeck, 1993), ${ }^{5}(\mathrm{Hu} \&$ Bentler, 1999), ${ }^{6}$ (Meyers, Gamst \& Guarino, 2006), ${ }^{7}$ (Byrne, 2010)

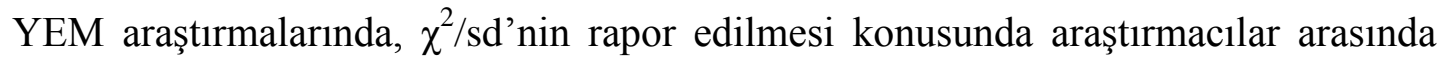
bir görüş birliği olsa da (Mulaik vd., 1989); diğer uyum indekslerinden hangilerinin rapor edilmesi gerektiğine ilişkin farklı araştırmacılar tarafından değişik öneriler getirilmiştir. McDonald ve Ho (2002); CFI, GFI, NFI ve NNFI (TLI); Garver ve Mentzer (1999); RMSEA, CFI ve NNFI (TLI); Brown (2006); RMSEA, SRMR, CFI ve NNFI (TLI); Iacobucci (2010), CFI ve SRMR uyum indekslerinin rapor edilmesini önermektedir. Gerbing ve Anderson (1992) ise, araştırmacının amacına bağlı olarak farklı uyum indekslerinin rapor edilebileceğini ifade etmektedir. Gerbing ve Anderson'a (1992) göre, "Araştırmalarda hangi uyum indeksleri rapor edilmelidir?" sorusunu yanitlamak, "Bir araba galerisindeki en iyi araba hangisidir?" sorusunu yanttlamak kadar zordur?". En iyi araba tanımı, kişinin amacına göre değişebildiği gibi, araştırmalarda rapor edilmesi gereken uyum indeksleri de araştırmacının amacına göre farklılık göstermektedir. Nasıl ki, bir birey için en iyi araba, en hızlı araba iken; başka bir birey için en iyi araba en güvenli araba olabiliyorsa, farklı amaçlara sahip olan araştırmacıların rapor edecekleri uyum indeksleri de farkl1lık gösterebilir. Bu araştırmada, herhangi bir modelin uyumunun değerlendirilmesi yerine; AMOS ve LISREL paket programlarından elde edilen analiz sonuçlarının karşılaştırılması amaçlandığından, analiz sonuçları rapor edilirken yukarıda sıralanan uyum indekslerinin tümüne yer verilmiştir.

\section{YÖNTEM}

$\mathrm{Bu}$ araştırmada, AMOS ve LISREL paket programları aracılığıyla gerçekleştirilen YEM analizlerine ilişkin uyum indekslerinin karşılaştırılmalı olarak incelenmesi amaçlanmaktadır. Dolayısıyla evren ve örneklem tayinine ihtiyaç duyulmamıştır. Araştırmada; yol analizi, DFA ve yapısal modele ilişkin analizler ayrı veri setleri üzerinden yürütülmüştür. AMOS ve LISREL programları arasındaki tutarlığın, analiz edilen modelin uyum düzeyine göre değişip değişmediğini belirleyebilmek için araştırmada düşük ve yüksek uyum gösteren modellerin kullanılmasına dikkat edilmiştir. Daha önceki araştırmalarda; yol analizi, DFA ve yapısal model gibi değişik YEM modelleri için farklı 
paket programlarda hesaplanan uyum indeksleri karşılaştırılmıştır. Bu araştırmalar, farklı YEM programlarından elde edilen uyum indeksleri arasındaki tutarlılı̆̆n analiz edilen modelin türünden etkilenmediğini ortaya koymuştur. Bu nedenle; düşük, kabul edilebilir ve yüksek uyum gösteren veri setlerinin YEM çatısı altında yer alan farklı modellere (yol analizi, DFA ve yapısal model) karşılık gelmesinde bir sakınca görülmemiştir. Veri setlerinin düşük, kabul edilebilir ve yüksek uyum gösteren model şeklinde sınıflandırılmasında, uyum indekslerine ilişkin Tablo 1'de sunulan kabul edilebilir ve mükemmel uyum aralıkları referans alınmıştır.

Araştırmada kullanılan veri setlerinin her üçü de normallik varsayımını karşılamaktadır. Dolayısıyla, her iki programda da veriler en yüksek olabilirlik (Maximum Likelihood) yöntemi kullanılarak analiz edilmiştir. LISREL programı analiz çıktılarını sunarken, kendinden tanımlı (default) bir özellik olarak virgülden sonra iki basamak rapor etmektedir. Ancak araştırmacı, analizler için yazılan syntax'lara "Number of Decimals" komutunu ekleyerek virgülden sonra rapor edilecek basamak sayısında değişiklik yapabilmektedir (Jöreskog \& Sörbom, 1993). AMOS programında ise, virgülden sonra üç basamak rapor edilmektedir. AMOS ve LISREL paket programları karşılaştırılırken, iki programın virgülden sonra rapor ettiği basamak sayısının farklı olmasından dolayı oluşabilecek etkileri kontrol altına almak için LISREL paket programına virgülden sonra üç basamak rapor etmesi talimatı verilmiştir. $\mathrm{Bu}$ doğrultuda LISREL paket programında analizler için yazılan syntax'lara "Number of Decimals: 3" komutu eklenmiştir. LISREL ve AMOS paket programlarının kendinden tanımlı diğer bazı özellikleri ise iki programdan elde edilen uyum indeksleri arasındaki fark1 etkilemeyeceğinden, bu özelliklerde herhangi bir değişikliğin yapılmasına gerek duyulmamıştır. Örneğin; LISREL paket programı kendinden tanımlı bir özellik olarak, 7.882'nin üzerindeki modifikasyon indekslerini rapor etmektedir (Jöreskog \& Sörbom, 1993). AMOS paket programı ise, analiz çıktılarında yalnızca 4'ün üzerinde değere sahip olan modifikasyon indekslerini sunmaktadır (Arbuckle, 2010). LISREL ve AMOS programlarının analiz çıktılarında sunulacak modifikasyon indekslerine ilişkin bu özellikleri, uyum indeksi değerlerini etkilememektedir. Bundan dolayı, programlara rapor edilecek modifikasyon indekslerinin aralığ ile ilgili herhangi bir talimat verilmemiştir. LISREL ve AMOS paket programları arasındaki bir diğer farklılık gözlenen değişkenlere ait ölçüm hatalarının araştırmacı tarafından mı çizildiği; yoksa program tarafından $\mathrm{m} 1$ modele eklendiğidir. LISREL paket programında gözlenen değişkenlere ait ölçüm hataları kendinden tanımlı bir özellik olarak analize dâhil olmakta ve ölçüm hatalarının araştırmacı tarafından çizilmesine gerek kalmamaktadır. AMOS paket programında ise, gözlenen değişkenlere ait ölçüm hatalarının araştırmacı tarafından çizilmesi gerekmektedir. Araştırmada kullanılan veri setlerine ilişkin özellikler aşağıda açıklanmıştır.

\section{Yol Analizi Modelinde Kullanulan Veri Seti}

Yol analizinde kullanılan veri dosyası, Şimșek'in (2007) "Yapısal Eşitlik Modellemesi'ne Giriş Temel İlkeler ve Uygulamalar" adlı kitabında yer verilen GOZLEN adlı veri seti kısmen değiştirilerek oluşturulmuştur. Bu kapsamda, GOZLEN adlı veri setindeki beş gözlenen değişkenden biri veri dosyasından çıkarılmış ve diğer dört gözlenen değişkene ait değerlerde bir takım değişiklikler yapılmıştır. Uygulanan değişikliklerin ardından veri dosyasında kalan gözlenen değişkenler; F1, F2, F3 ve F4 şeklinde adlandırılmıştır. Modelde; F1 ve F2 değişkenleri arasında ilişki olduğu, F1 ve F2 değişkenlerinin her ikisinin F3 değişkenini etkilediği, F1 ve F2 değişkenlerinin F3 değişkeninin aracılığıyla F4 değişkeni üzerinde dolaylı bir etkiye sahip olduğu, F1 ve F2 
değişkenlerinin F4 değişkeni üzerinde doğrudan bir etkisinin bulunmadığg öngörülmektedir. Modele ilişkin analizler 100 kişiden oluşan bir veri dosyası üzerinden yürütülmüştür.

\section{DFA Modelinde Kullanulan Veri Seti}

DFA'da kullanılan veri seti, 2 gizil değişkenden oluşan bir modeldir. Modeldeki gizil değişkenler; F1 ve F2 olarak adlandırılmıştır. Modelde; F1 ve F2 gizil değişkenleri arasında anlamlı ilişki bulunduğu ve F1 gizil değişkenin 5, F2 gizil değişkenin ise 4 gözlenen değişken ile temsil edildiği öngörülmektedir. Modele ilişin analizler, 300 kişiden oluşan bir veri dosyası üzerinden gerçekleştirilmiştir. Bu veri dosyası, araştırmacıların daha önce yaptıkları bir çalışmaya (İlhan \& Çetin, 2013a) ait veri setinin kısmen değiştirilmesiyle oluşturulmuştur. Yapılan değişiklik kapsamında, veri setindeki katılımcı sayısı 416'dan 300'e, F1 gizil değişkenini temsil eden gözlenen değişken sayısı 11'den 5'e ve F2 gizil değişkenini temsil eden gözlenen değişken sayısı 10'dan 4'e düşürülmüştür.

\section{Yaptsal Modelde Kullanulan Veri Seti}

Yapısal modelde kullanılan veri seti; X1, X2, X3, X4, Y1, Y2 ve Y3 şeklinde 7 gözlenen değişkenden oluşmaktadır. Modelde, X1, X2, X3 ve X4 gözlenen değişkenleri ile ölçülen F1 yapısının; Y1, Y2 ve Y3 gözlenen değişkenleriyle ölçülen F2 yapısının anlamlı bir yordayıcısı olduğu öngörülmektedir. Modele ilişkin analizler 300 kişiden oluşan bir veri dosyası üzerinden yürütülmüştür. $\mathrm{Bu}$ veri seti de, araştırmacılar tarafından daha önce yapılan bir araştırmanın (İlhan \& Çetin, 2013b) verileri kısmen değiştirilerek elde edilmişstir. Bu doğrultuda, veri setindeki gizil değişken sayısı 3'ten 2'ye ve katılımc1 sayısı 326'dan 300'e düşürülmüştür. Ayrıca, kalan 2 gizil değişkeni ölçen gözlenen değişken sayıları; sırasıyla 13 yerine 4 ve 6 yerine 3 olarak belirlenmiştir.

\section{BULGULAR}

Bu bölümde, LISREL ve AMOS paket programları kullanılarak gerçekleştirilen yol analizi, DFA ve yapısal modele ilişkin analiz çıktıları sunulmuştur. Analiz çıktıları sunulurken, ilk olarak, analiz edilen modelin şekilsel gösterimine yer verilmiş, ardından LISREL ve AMOS programlarından elde edilen uyum indeksleri karşılaştırmalı olarak incelenmiştir.

\section{Yol Analizi Modeli için LISREL ve AMOS Programlarından Elde Edilen Analiz Çıktıları}

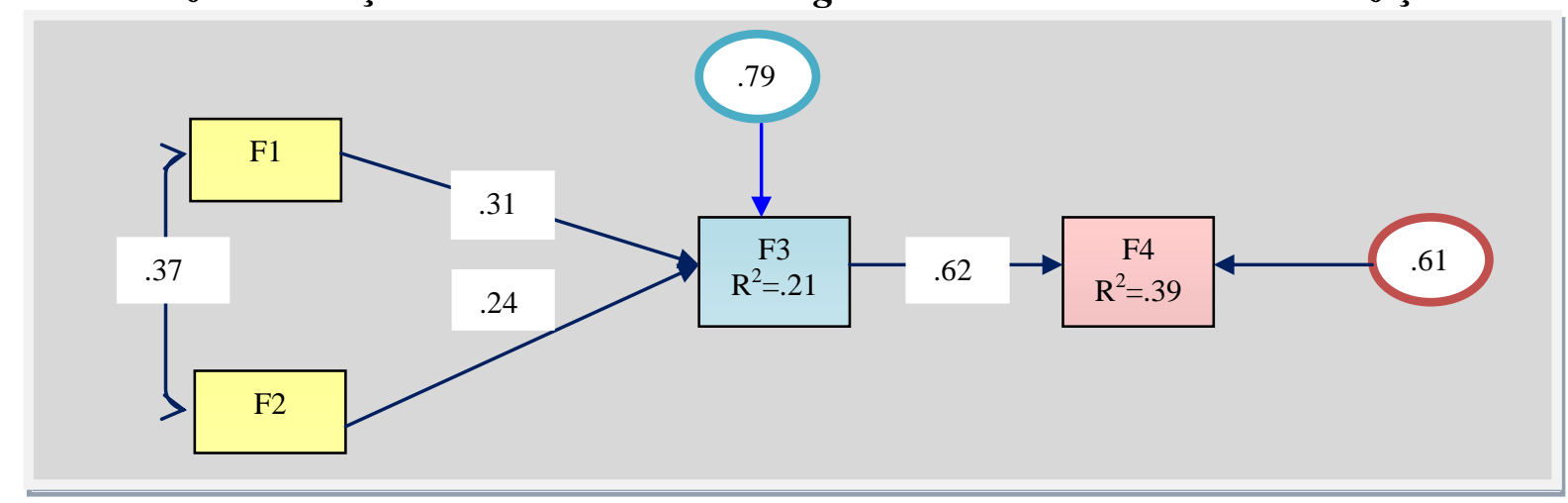

Şekil 4: LISREL ve AMOS Programlarından Elde Edilen Yol Analizi Modeli

Şekil 4'te, LISREL ve AMOS programlarından elde edilen yol analizi modeli görülmektedir. Analiz sonucunda, yol analizi modeline ilişkin LISREL ve AMOS 
programından elde edilen parametre kestirimlerinin eşit olduğu belirlenmiştir. LISREL ve AMOS programları ile gerçekleştirilen yol analizinden elde edilen uyum indeksleri Tablo 2'de sunulmuştur.

Tablo 2. LISREL ve AMOS Programlart ile Gerçekleştirilen Yol Analizinden Elde Edilen Uyum İndeksi Değerleri

\begin{tabular}{lccc}
\hline $\begin{array}{l}\text { İncelenen } \\
\text { Uyum } \\
\text { Indeksleri }\end{array}$ & $\begin{array}{c}\text { LISREL Programından } \\
\text { Elde Edilen Uyum } \\
\text { Indeksleri Değerleri }\end{array}$ & $\begin{array}{c}\text { AMOS Programından Elde } \\
\text { Edilen Uyum İndeksi } \\
\text { Değerleri }\end{array}$ & $\begin{array}{c}\text { İki Programdan Elde } \\
\text { Edilen Uyum İndeksleri } \\
\text { Arasindaki Farklar }\end{array}$ \\
\hline$\chi^{2} /$ sd & 4.575 & 4.799 & $\mathbf{0 , 2 2 4}$ \\
GFI & .956 & .956 & 0 \\
AGFI & .779 & .779 & 0 \\
CFI & .928 & .916 & $\mathbf{0 , 0 1 2}$ \\
NFI & .914 & .90 & $\mathbf{0 , 0 1 4}$ \\
NNFI (TLI) & .785 & .748 & $\mathbf{0 , 0 3 7}$ \\
RFI & .743 & .701 & $\mathbf{0 , 0 4 2}$ \\
IFI & .931 & .919 & $\mathbf{0 , 0 1 2}$ \\
RMSEA & 0.192 & .196 & 0,004 \\
RMR & 1.709 & 1.691 & $\mathbf{0 , 0 1 8}$ \\
SRMR & .0765 & .0765 & 0,005 \\
PNFI & .305 & .305 & 0 \\
PGFI & .191 & .191 & 0,001 \\
AIC & 25.149 & 25.598 & $\mathbf{0 , 4 4 9}$ \\
CAIC & 53.991 & 54.440 & $\mathbf{0 , 4 4 9}$ \\
ECVI & .259 & .259 & 0 \\
\hline
\end{tabular}

Tablo 2'deki bulgulara göre; GFI, AGFI, RMSEA, SRMR, PNFI, PGFI ve ECVI indeksleri için LISREL ve AMOS programlarından elde edilen değerler arasındaki farkın .01 ölçütünü (Cheung \& Rensvold, 2002; Hox, 1995) aşmadığı belirlenmiştir. Bu ölçüt, Hox (1995) ile Cheung ve Rensvold (2002) tarafından yapılan çalışmalarda ölçüm değişmezliği kriteri olarak .01 değerinin esas alınması önerisinden yola çıkılarak belirlenmiştir. $\chi^{2} / \mathrm{sd}$, CFI, NFI, NNFI/TLI, RFI, IFI, RMR indeksi için ise LISREL ve AMOS programından elde edilen değerler arasındaki farkın .01 ölçütünü aştığı belirlenmiştir. Ancak; CFI, NFI, IFI indeksleri için LISREL ve AMOS programından elde edilen değerler arasındaki farkın virgülden sonraki üçüncü basamağında gerekli yuvarlamalar yapıldığında, bu uyum indeksleri için de iki programda hesaplanan değerler arasındaki farkın .01 ölçütünü aşmadığı söylenebilir. Ayrıca, AIC, CAIC ve ECVI uyum indeksleri için kabul edilebilir ya da mükemmel uyum ölçütü olarak alınan sabit bir aralık olmadığı ve bu uyum indekslerinin 0 ile 1 arasında değişen değerler alabilen uyum indekslerinden farklı olarak daha yüksek değerler alabildiği göz önünde bulundurulduğunda, bu uyum indeksleri için iki programdan elde edilen değerler arasındaki farkın ihmal edilebilecek büyüklükte olduğu düșünülebilir. Buna göre, iki programdan elde edilen uyum indeksleri arasındaki farkın özellikle, $\chi^{2} / \mathrm{sd}$, NNFI (TLI) ve RFI indeksleri için belirgin olduğu ifade edilebilir. 


\section{DFA Modelinden Elde Edilen Analiz Çıktıları}

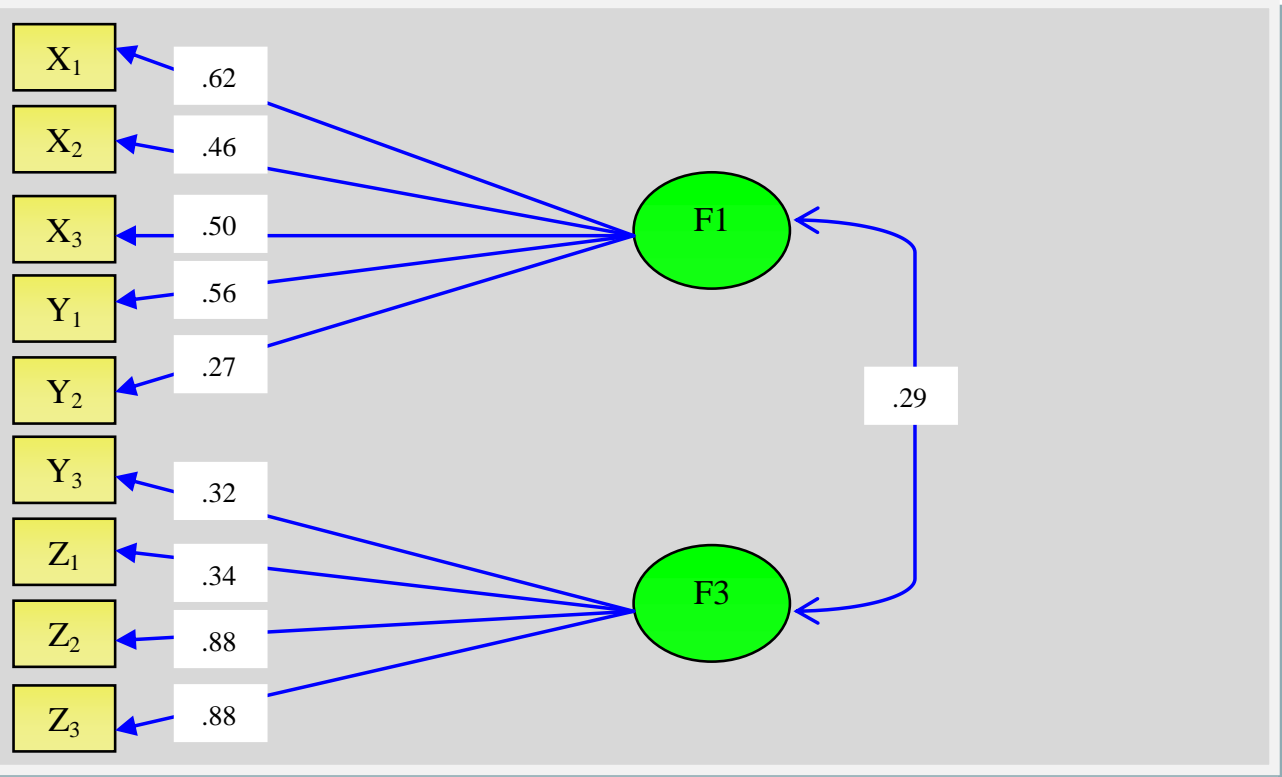

Şekil 5. LISREL ve AMOS Programlarından Elde Edilen DFA Çıktılarına İlişkin Ölçüm Modeli ve Faktör Yükleri

Şekil 5'te, LISREL ve AMOS programlarından elde edilen DFA çıktılarına ilişkin ölçüm modeli ve faktör yükleri görülmektedir. Analiz sonucunda, DFA modeline ilişkin LISREL ve AMOS programından elde edilen faktör yükleri, standart hata, hata varyansı ve tahmin (estimates) değerlerinin eşit olduğu belirlenmiştir. LISREL ve AMOS programları ile gerçekleştirilen DFA'dan elde edilen uyum indeksleri Tablo 3'te sunulmuştur.

Tablo 3. LISREL ve AMOS Programlart ile Gerçekleştirilen DFA Analizinden Elde Edilen Uyum Indeksi Değerleri

\begin{tabular}{lccc}
$\begin{array}{l}\text { İncelenen } \\
\text { Uyum }\end{array}$ & $\begin{array}{c}\text { LISREL Programından } \\
\text { İndeksleri Edilen Uyum } \\
\text { İndeksleri Degerleri }\end{array}$ & $\begin{array}{c}\text { AMOS Programindan Elde } \\
\text { Edilen Uyum İndeksi } \\
\text { Değerleri }\end{array}$ & $\begin{array}{c}\text { İki Programdan Elde } \\
\text { Edilen Uyum İndeksleri } \\
\text { Arasındaki Farklar }\end{array}$ \\
\hline$\chi^{2} /$ sd & 2.749 & 2.546 & $\mathbf{0 , 2 0 3}$ \\
GFI & .950 & .950 & 0 \\
AGFI & .913 & .913 & 0 \\
CFI & .922 & .914 & 0,008 \\
NFI & .879 & .869 & 0,01 \\
NNFI (TLI) & .891 & .881 & 0,01 \\
RFI & .833 & .817 & $\mathbf{0 , 0 1 6}$ \\
IFI & .923 & .916 & 0,007 \\
RMSEA & .076 & .072 & 0,004 \\
RMR & .066 & .066 & 0 \\
SRMR & .0618 & .0618 & 0 \\
PNFI & .635 & .628 & 0,007 \\
PGFI & .549 & .549 & 0 \\
AIC & 109.494 & 104.194 & $\mathbf{5 , 3}$ \\
CAIC & 198.866 & 193.566 & $\mathbf{5 , 3}$ \\
\hline ECVI & .366 & .348 & $\mathbf{0 1 8}$ \\
\hline
\end{tabular}

Tablo 3'e göre; GFI, AGFI, CFI, NFI, NNFI (TLI), IFI, RMSEA, RMR, SRMR, PNFI ve PGFI indeksleri için AMOS ve LISREL programlarından elde edilen değerler 
arasındaki farkın çalışma kapsamında esas alınan .01 ölçütünü aşmadığı tespit edilmiştir. $\mathrm{Bu}$ bulguya dayanarak, LISREL ve AMOS programları ile gerçekleştirilen DFA'dan söz konusu uyum indeksleri için elde edilen değerlerin büyük ölçüde tutarlı olduğu söylenebilir. $\chi^{2} /$ sd, RFI, AIC, CAIC ve ECVI indeksleri için LISREL ve AMOS programlarından elde edilen uyum indeksleri arasındaki farkın .01 ölçütünü aştığı belirlenmiştir. Ancak daha önce de dile getirildiği üzere; AIC, CAIC ve ECVI indeksleri için kabul edilebilir ya da mükemmel uyum ölçütü olarak alınan mutlak bir aralık bulunmamakta ve bu uyum indeksleri 0 ile larasında değişen değerlere sahip olan uyum indekslerinin aksine daha yüksek değerler alabilmektedir. Bu nedenle; AIC, CAIC ve ECVI indeksleri için iki programdan elde edilen değerler arasındaki farkın ihmal edilebilecek büyüklükte olduğu ifade edilebilir. Buna göre, iki programdan elde edilen uyum indeksleri arasındaki farkın özellikle, $\chi^{2} /$ sd ve RFI indekslerinde belirgin olduğu söylenebilir.

Yapısal Model için LISREL Programından Elde Edilen Analiz Çıktıları

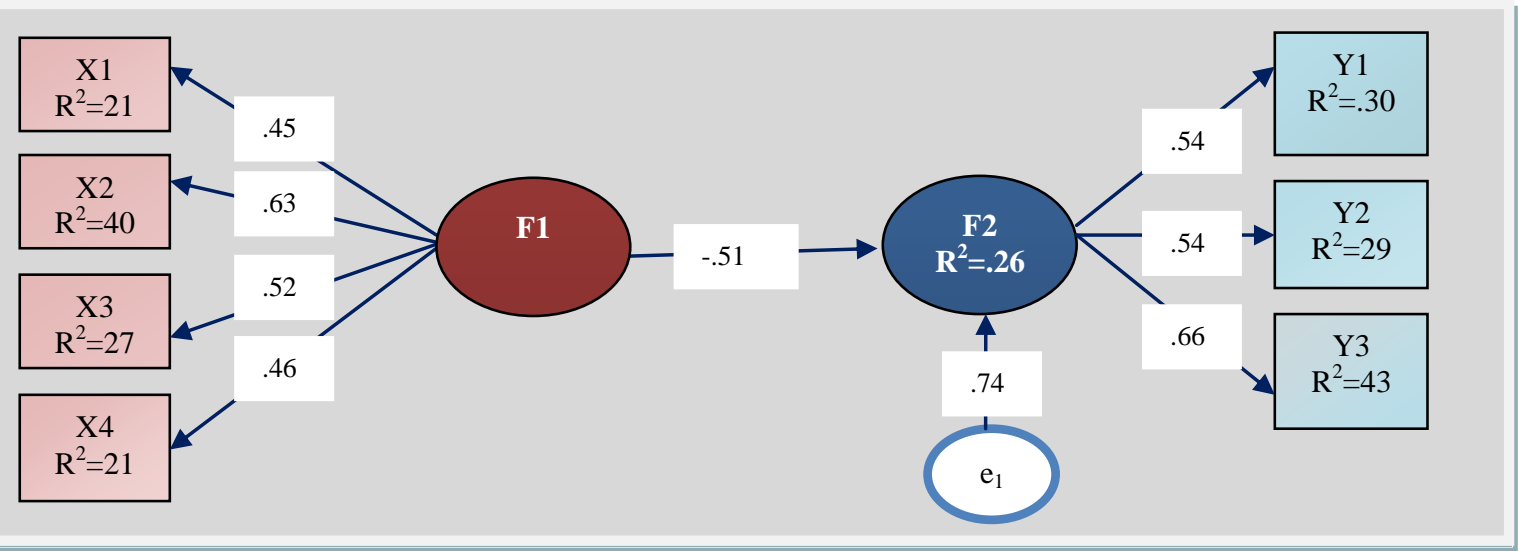

Şekil 6: LISREL ve AMOS Programlarından Elde Edilen Yapısal Model

Şekil 6'da, LISREL ve AMOS programlarından elde edilen yapisal model görülmektedir. Analiz sonucunda, yapısal modele ilişkin olarak LISREL ve AMOS programından elde edilen parametre kestirimlerinin eşit olduğu belirlenmiştir. LISREL ve AMOS programları ile gerçekleştirilen yapısal model analizinden elde edilen uyum indeksleri ise Tablo 4'te sunulmuştur. 
Tablo 4. LISREL ve AMOS Programları ile Gerçekleştirilen Yapısal Model Analizinden Elde Edilen Uyum Indeksi Dĕ̌gerleri

\begin{tabular}{lccc}
$\begin{array}{l}\text { İncelenen } \\
\text { Uyum } \\
\text { İndeksleri }\end{array}$ & $\begin{array}{c}\text { LISREL Programından } \\
\text { Elde Edilen Uyum } \\
\text { İndeksleri Değerleri }\end{array}$ & $\begin{array}{c}\text { AMOS Programindan Elde } \\
\text { Edilen Uyum İndeksi } \\
\text { Değerleri }\end{array}$ & $\begin{array}{c}\text { İki Programdan Elde } \\
\text { Edilen Uyum İndeksleri } \\
\text { Arasındaki Farklar }\end{array}$ \\
\hline$\chi^{2} /$ sd & .956 & .956 & 0 \\
GFI & .988 & .988 & 0 \\
AGFI & .975 & .975 & 0 \\
CFI & 1.00 & 1.00 & 0 \\
NFI & .961 & .948 & $\mathbf{0 , 0 1 3}$ \\
NNFI (TLI) & 1.003 & 1.004 & 0,001 \\
RFI & .938 & .916 & $\mathbf{0 , 0 2 2}$ \\
IFI & 1.002 & 1.003 & $-0,001$ \\
RMSEA & .00 & .00 & 0 \\
RMR & .043 & .043 & 0 \\
SRMR & .0295 & .0295 & 0 \\
PNFI & .595 & .587 & 0,008 \\
PGFI & .459 & .459 & 0 \\
AIC & 42.440 & 42.430 & 0,01 \\
CAIC & 113.001 & 112.987 & $\mathbf{0 , 0 1 4}$ \\
ECVI & .144 & .142 & 0,002 \\
\hline
\end{tabular}

Tablo 4 incelendiğinde; $\chi^{2}$ /sd, GFI, AGFI, CFI, RMSEA, RMR, SRMR, NNFI/TLI, IFI PGFI ve ECVI indeksleri için AMOS ve LISREL programlarından elde edilen değerler arasındaki farkın, araştırmada ölçüt olarak alınan .01 değerini (Cheung \& Rensvold, 2002; Hox, 1995) aşmadığı saptanmıştır. NFI, RFI ve CAIC indeksleri için ise LISREL ve AMOS programından elde edilen değerler arasındaki farkın sırasıyla .013, .022 ve .014 olup .01 ölçütünü aştığı belirlenmiştir. Ancak, bu farkların virgülden sonraki üçüncü basamağ1 için gerekli yuvarlamalar yapıldığında, iki programdan elde edilen uyum indeksleri arasındaki farkın yalnızca RFI indeksinde .01 ölçütünü aştığı söylenebilir. Düşük, kabul edilebilir ve mükemmel uyum gösteren üç ayrı veri seti için LISREL ve AMOS programlarından elde edilen uyum indeksleri arasındaki farklar Tablo 5'te ayrıca sunulmuştur.

Tablo 5. Düşük, Kabul Edilebilir ve Mükemmel Uyum Gösteren Modeller için LISREL ve AMOS Programindan Hesaplanan Uyum İndeksleri Arasındaki Farklar

\begin{tabular}{lccc}
\hline $\begin{array}{l}\text { Uyum } \\
\text { İndeksleri }\end{array}$ & $\begin{array}{c}\text { Dü̈sük Uyum } \\
\text { Gösteren Model }\end{array}$ & $\begin{array}{c}\text { Kabul Edilebilir Uyum } \\
\text { Gösteren Model }\end{array}$ & $\begin{array}{c}\text { Mükemmel Uyum } \\
\text { Gösteren Model }\end{array}$ \\
\hline$\chi^{2} /$ sd & 0,224 & 0,203 & 0 \\
GFI & 0 & 0 & 0 \\
\hline AGFI & 0 & 0 & 0 \\
\hline CFI & 0,012 & 0,008 & 0 \\
\hline NFI & 0,014 & 0,01 & 0,013 \\
\hline NNFI (TLI) & 0,037 & 0,01 & 0,001 \\
\hline RFI & 0,042 & 0,016 & 0,022 \\
IFI & 0,012 & 0,007 & $-0,001$ \\
RMSEA & 0,004 & 0,004 & 0 \\
\hline RMR & 0,018 & 0 & 0 \\
\hline SRMR & 0,005 & 0 & 0 \\
\hline PNFI & 0 & 0,007 & 0,008 \\
PGFI & 0,001 & 0 & 0 \\
\hline AIC & 0,449 & 5,3 & 0,01 \\
CAIC & 0,449 & 5,3 & 0,014 \\
ECVI & 0 & 0,018 & 0,002 \\
\hline
\end{tabular}


Tablo 5'e bakıldığında, LISREL ve AMOS programlarında hesaplanan uyum indeksleri arasındaki farkın, genel olarak düşük uyum gösteren modelde daha fazla olduğu belirlenmiştir. Özellikle, model uyumunun tespitinde ilk incelenen uyum indeksi olan $\chi^{2} / \mathrm{sd}$ için iki programdan elde edilen uyum indeksleri arasındaki farkın modelin uyumu düştükçe yükseldiği görülmektedir. Tablo 5'e göre ayrıca, RFI indeksinin; mükemmel, kabul edilebilir ve düşük uyum gösteren modellerin her üçünde de .01 ölçütünü aştı̆̆1 saptanmıştır. Bununla birlikte, bu uyum indeksi için iki programdan elde edilen değerler arasındaki farkın düşük uyum gösteren modelde daha fazla olduğu tespit edilmiştir. Düşük uyum gösteren modelde .01 ölçütünü aşan uyum indekslerinden bir diğeri, NNFI (TLI)'dır. NNFI indeksi için LISREL ve AMOS programlarından elde edilen değerler arasındaki farkın model uyumu düştükçe arttığı görülmektedir.

\section{TARTIŞMA ve SONUÇ}

$\mathrm{Bu}$ araştırmada; LISREL ve AMOS paket programları kullanılarak farklı uyum düzeylerine sahip olan yol analizi ve DFA modeli ile yapısal model analiz edilmiştir. Böylece, iki programdan elde edilen uyum indekslerinin ne derece tutarlı olduğu belirlenmeye çalışılmıştır. Araştırmada, model uyumunun mükemmel olduğu veri seti üzerinden yapılan analizlerde, LISREL ve AMOS programından elde edilen uyum indekslerinin büyük ölçüde eş değer olduğu belirlenmiştir. Bu bulgu, Peprah (2000) tarafından yapılan araştırmanın bulgularıyla paralellik göstermektedir. Peprah (2000), model ile veri seti arasındaki uyumunun mükemmel olduğu bir yapısal model üzerinden yürüttüğü çalışmasında, AMOS, EQS, LISREL, Mx, RAMONA ve SEPATH programlarında hesaplanan uyum indekslerinin büyük ölçüde eş değer olduğu sonucuna ulaşmıştır. Dolayısıyla, model ile veri seti arasındaki uyumunun yüksek olması halinde, araştırmada kullanılan YEM programının elde edilen uyum indeksi değerlerinde bir farklılığa yol açmadığı söylenebilir. Buna göre, model ile veri arasındaki uyumunun yüksek olduğu, aynı hipotezlerin test edildiği ancak farklı YEM programlarının kullanıldığ 1 çalışmalardan elde edilen bulguların kullanılan programdan bağımsız olarak karşılaştırılabileceği söylenebilir.

Araştırmada; $\chi^{2} / \mathrm{sd}$, NNFI ve RFI indeksleri başta olmak üzere, AMOS ve LISREL paket programlarından elde edilen uyum indeksleri arasındaki farkın, model ile veri seti arasındaki uyumun düşük olduğu modelde, model ile veri seti arasındaki uyumunun yüksek olduğu modele kıyasla daha büyük olduğu saptanmıştır. Bu bulgu, iki programdan elde edilen uyum indeksleri arasındaki farkın analiz edilen modelin uyumuna göre değişebildiğini ve düşük uyum gösteren modellerde farkın daha yüksek olduğunu göstermektedir. Diğer bir deyişle; araştırmada ulaşılan bulgular, analiz edilen modelin uyum düzeyinin LISREL ve AMOS programlardan elde edilen uyum indeksi değerleri arasındaki fark üzerinde etkili olabildiğine işaret etmektedir. Bu nedenle; aynı probleme yanıt aranan ancak, değişik YEM programlarından yararlanılan ve model uyumunun yüksek olmadığ çalışmalarda, kullanılan YEM programının araştırmadan elde edilen uyum indeksleri üzerinde etkisinin olabileceği göz ardı edilmemelidir.

\section{KAYNAKLAR}

Albright, J.J., \& Park, H.M. (2008). Confirmatory factor analysis using AMOS, LISREL, Mplus and SAS/STAT CALIS. Technical Working Paper: Indiana University.

Arbuckle, J. (2010). AMOS user's guide. Chicago, IL: Small Waters.

Arbuckle, J. \& Wothke, W. (1999). AMOS user's guide. Chicago, IL: Small Waters.

Arminger, G. (1997). MECOSA 3. Behaviormetrika, 24(1), 102-104.

Bagozzi, R.P., \& Heatherton, T.F. (1994). A general approach to representing multifaceted personality constructs: Application to state self-esteem. Structural Equation Model, 1(1), 35-67.

Bagozzi, R.P., \& Yi, Y. (1988). On the evaluation of structural equation models. Journal of the Academy of Marketing Science, 16(1), 74-94. 
Baumgartner, H., \& Homburg, C. (1996). Applications of structural equation modeling in marketing and consumer research: A review. International Journal of Research in Marketing, 13(2), 139-161.

Bayram, N. (2010). Yapısal eşitlik modellemesine giriş AMOS uygulamaları. İstanbul: Ezgi Kitabevi.

Bentler, P.M. (1980). Multivariate analysis with latent variables: Causal modeling. Annual Review of Psychology, 31, 419-456.

Bentler, P.M. (2004). EQS structural equations program manual. Encino, CA: Multivariate Software, Inc.

Bentler, P.M., \& Bonett, D.G. (1980). Significance tests and goodness of fit in the analysis of covariance structures. Psychological Bulletin, 88, 588-606.

Bentler, P.M., \& Yuan, K.H. (1999). Structural equation modeling with small samples: Test statistics. Multivariate Behavioral Research, 34(2), 181-197.

Boker, S., Neale, M., Maes, H., Wilde, M., Spiegel, M., Brick, T. vd. (2011). OpenMx: An open source extended structural equation modeling framework. Psychometrika, 76, 306-317.

Bordens, K.S., \& Abbott, B.B. (2011). Research design and methods: A process approach. New York: The McGraw-Hill Companies.

Brown, T.A. (2006). Confirmatory factor analysis for applied research. New York: The Guilford Press.

Browne, M.W., \& Cudeck, R. (1993). Alternative ways of assessing model fit. In: Bollen, K.A., \& Long, J.S. (Eds.), Testing structural equation models (pp. 136-162). Beverly Hills, CA: Sage

Browne, M.W., \& Mels, G. (2000). Path Analysis: RAMONA. In Systat 10.0: Statistics II (pp. 233-291). Chicago: SPSS.

Byrne, B.M. (2001). Structural equation modeling with AMOS, EQS, and LISREL: Comparative approaches to testing for the factorial validity of a measuring instrument. International Journal of Testing, 1(1), 5586.

Cheung, G.W., \& Renswold, R.B. (2002). Evaluating goodness-of-fit indexes for testing measurement invariance, structural equation modeling. A Multidisciplinary Journal, 9(2), 233-255.

Clayton, M.F., \& Pett, M. A. (2008). AMOS versus LISREL: One data set, two analyses. Nursing Research, 57(4), 283-292.

Çokluk, Ö., Şekercioğlu, G., \& Büyüköztürk, Ş. (2012). Sosyal bilimler için çok değişkenli istatistik: SPSS ve LISREL uygulamaları. Ankara: Pegem Akademi Yayıncılık.

Ferrer, E. Hamagami, F., \& McArdle, J.J. (2004). Modeling latent growth curves with incomplete data using different types of structural equation modeling and multilevel software. Structural Equation Modeling, 11(3), 452-483.

Fraser, C., \& McDonald, R.P. (1988). COSAN: Covariance structure analysis. Multivariate Behavioral Research, 23, 258-348.

Davey, A., \& Savla, J. (2010). Statistical power analysis with missing data: A structural equation modeling approach. New York: Routledge.

Garver, M.S., \& Mentzer, J.T. (1999). Logistics research methods: Employing structural equation modeling to test for construct validity. Journal of Business Logistics, 20(1), 33-57.

Gerbing, D.W., \& Anderson, J.C. (1985). The effects of sampling error and model characteristics on parameter estimation for maximum likelihood confirmatory factor analysis. Multivariate Behavioral Research, 20, 255-271.

Gerbing, D.W., \& Anderson, J.C. (1992). Monte carlo evaluations of goodness of fit indices for structural equation models. Sociological Methods and Research, 21(2), 132-160.

Hair, J.F., Anderson, R.E., Tatham, R.L. \& Black, W.C. (1998). Multivariate data analysis. Englewood Cliffs, New Jersey: Prentice Hall.

Hershberger, S.L. (2003). The growth of structural equation modeling: 1994-2001. Structural Equation Modeling: A Multidisciplinary Journal, 10(1), 35-46.

Hoe, S.L. (2008). Issues and procedures in adopting structural equation modeling technique. Journal of Applied Quantitative Methods, 3(1), 76-83.

Hooper, D., Coughlan, J., \& Mullen, M. (2008). Structural equation modeling: Guidelines for determining model fit. Electronic Journal of Business Research Methods, 6(1), 53-60.

Hox, J.J. (1995). AMOS, EQS and LISREL for Windows: A comparative review. Structural Equation Modeling: A Multidisciplinary Journal, 2(1), 79-91.

Hox, J.J., \& Bechger, T.M. (1998). An Introduction to Structural Equation Modeling. Family Science Review, 11, 354-373.

Hoyle, R.H. (1995). The structural equation modeling approach. In R.H. Hoyle (Ed.), Structural equation modeling: Concepts, issues, and applications (pp. 1-15). Thousand Oaks, CA: Sage. 
Hu, L., \& Bentler, P.M. (1999). Cutoff criteria for fit indexes in covariance structure analysis: Conventional criteria versus new alternatives. Structural Equation Modeling, 6(1), 1-55.

Iacobucci, D. (2010). Structural equations modeling: Fit indices, sample size, and advanced topics. Journal of Consumer Psychology, 20, 90-98.

İlhan, M., \& Çetin, B. (2013a). Matematik öğrenme yaklaşımları ölçeği'nin (MÖYÖ) geliştirilmesi: Geçerlik ve güvenirlik çalışması. Bartın Üniversitesi Ĕ̆itim Fakültesi Dergisi, 2(2), 113-145.

İlhan, M., \& Çetin, B. (2013b). Ortaokul öğrencilerinin matematik odaklı akademik risk alma davranışları: Bir ölçek geliştirme çalışması. E-uluslararası Eğitim Araştırmaları Dergisi, 4(2), 1-28.

Jöreskog, K.G., \& Sörbom, D. (1993). LISREL 8: User's guide. Chicago: Scientific Software.

Jöreskog, K., \& Sörbom, D. (2000). LISREL [Computer Software]. Lincolnwood, IL: Scientific Software, Inc.

Kahn, J.H. (2006). Factor analysis in counseling psychology research, training, and practice: Principles, advances and applications. The Counseling Psychologist, 34(5), 684-718.

Kline, R.B. (2011). Principles and practice of structural equation modeling. New York: The Guilford Press.

Leech, N.L., Barrett, K.C., \& Morgan, G.A. (2005). SPSS for intermediate statistics; Use and interpretation. Mahwah, NJ: Lawrence Erlbaum Associates.

Lei, P.W., \& Wu, Q. (2007). Introduction to structural equation modeling: issues and practical considerations. Educational Measurement: Issues and Practice, 26(3), 33-43.

Marsh, H.W., Hau, K.T., Artelt, C., Baumert, J., \& Peschar, J.L. (2006). OECD's brief self-report measure of educational psychology's most useful affective constructs: Cross-cultural, psychometric comparisons across 25 countries. International Journal of Testing, 6(4), 311-360.

Meydan, C.H., \& Şeşen, H. (2011). Yapısal eşitlik modellemesi ve AMOS uygulamaları. Ankara: Detay Yayıncilik.

Mulaik, S.A. (2009). Linear causal modeling with structural equations. Boca Raton, FL: Chapman \& Hall/CRC.

Mulaik, S.A., James, L.R., Alstine, J.A, Bennet, N., Lind, S., \& Stilwell, C.D. (1989). Evaluation of goodnessof-fit indices for structural equation models. Psychological Bulletin, 105(3), 430-445.

Muthen, B.O. (1987). LISCOMP. Analysis of linear structural equations with a comprehensive measurement model. Theoretical integration and user's guide. Mooresville, IN: Scientific Software.

Muthén, B.O., \& Muthén, L. (2004). Mplus user's guide. Los Angeles, CA: Muthén\& Muthén.

Neale, M. C., Boker, S.M., Xie, G., \& Maes, H.H. (2004). Mx: Statistical Modeling. Richmond: Virginia Commonwealth University.

Pallant, J. (2005). SPSS survival manual: A step by step guide to data analysis using SPSS for windows. Australia: Australian Copyright.

Pedhazur, E.J. (1997). Multiple regression in behavioral research: Explanation and prediction. New York: Holt, Rinehart \& Winston.

Peprah, S. (2000). On using AMOS, EQS, LISREL, Mx, RAMONA \& SEPATH for structural equation modeling. (Unpublished Master Thesis, University of Port Elizabeth, Güney Afrika). http://contentpro.seals.ac.za/iii/cpro/DigitalItemPdfViewerPage.external?id=2834223215252957\&item $\underline{\mathrm{Id}=1005753 \& \text { lang=eng\&file }=\% 2 \text { Fiii } \% 2 F c p r o \% 2 F a p p \% 3 F i d \% 3 \mathrm{D} 2834223215252957 \% 26 \mathrm{itemId} \% 3 \mathrm{D}}$ 1005753\%26lang\%3Deng\%26nopassword\%3Dtrue\%26service\%3Dblob\%26suite\%3Ddef\#locale=eng \&gridView=true adresinden edinilmiştir.

PROC CALIS. (2009). Computer Software Manual. Cary, SAS Institute, Inc.

Raykov, T., \& Marcoulides, G.A. (2006). A first course in structural equation modeling. Mahwah, NJ: Lawrence Erlbaum.

Reisinger, Y., \& Mavondo, F. (2007): Structural equation modeling. Journal of Travel \& Tourism Marketing, 21(4), 41-71.

Reisinger, Y., \& Turner, L. (1999). Structural equation modeling with LISREL: Application in tourism. Tourism Management, 20(1), 71-88.

Rossel, Y. (2012). Iavaan: An R package for structural equation modeling. Journal of Statistical Software, 48(2), 1-36.

Schermelleh-Engel, K., \& Moosbrugger, H. (2003). Evaluating the fit of structural equation models: Tests of significance and descriptive goodness-of-fit measures. Methods of Psychological Research Online, 8(2), 23-74.

Schoenberg, R., \& Arminger, G. (1988). LINCS 2: A program for linear covariance structure analysis. Kensington MD: RJS Software.

Schreiber, B., Stage, F.K., King, J., Nora, A., \& Barlow, E.A. (2006). Reporting structural equation modeling and confirmatory factor analysis results: A review. Journal of Educational Research, 99(6), 323-337.

Schumacker R.E., \& Lomax R.G. (2004). A beginner's guide to structural equation modeling. Mahwah, New Jersey: Lawrence Erlbaum Associates, Inc. 
Steiger, J.H. (1994). SEPATH-A statistica for windows structural equation modeling program. In F. Faulbaum (Eds), Softstat '93: advances in statistical software 4 (pp. 99-105). Stuttgart: Gustav Fischer Verlag.

Stevens, J.P. (2009). Applied multivariate statistics for the social sciences. New York: Routledge.

Şimşek, Ö.F. (2007). Yapısal eşitlik modellemesine giriş: Temel ilkeler ve LISREL uygulamaları. Ankara: Ekinoks Yayınları.

Tabachnick, B.G., \& Fidell, L.S. (2007). Using multivariate statistics. Boston, Pearson Education, Inc.

Ullman, J.B. (2001). Structural equation modeling. In B.G. Tabachnick \& L.S. Fidell (Eds.), Using multivariate statistics. Needham Heights, MA: Allyn \& Bacon.

Wetson, R., \& Gore Jr, P.A. (2006). A brief guide to structural equation model. The Counseling Psychologist, 34(5), 719-751.

Widaman, K.F., \& Thompson, J.S. (2003). On specifying the null model for incremental fit indices in structural equation modeling. Psychological Methods, 8(1), 16-37.

Yılmaz, V., \& Çelik, H.E. (2009). LISREL ile yapısal eşitlik modellemesi-I temel kavramlar, uygulamalar, programlama. Ankara: Pegem Akdemi Yayınları.

\section{EXTENDED ABSTRACT}

\section{Introduction}

This study aimed to compare the analysis results obtained through LISREL and AMOS for the models of path analysis, Confirmatory Factor Analysis (CFA) and structural regression, which are within SEM and differ in levels of fit. There is great number of programs which have been developed to carry out SEM (Structural equation modeling) analyses; thus, it does not seem to be possible to discuss all programs in a single research. Therefore, the research was limited to LISREL and AMOS (Albright \& Parker, 2008) packages which are popular (Hox \& Bechger, 1998; Reisinger \& Turner, 1999; Rossel, 2012), user-friendly and most commonly preferred for SEM analyses by researchers.

\section{Method}

In the study, space and sample determinations were not needed since fit indices of SEM analyses by AMOS and LISREL packages were aimed to be comparatively examined. The study was conducted on three different sets of data that reflected the models through a data file. The data set used in the path analysis was determined to reflect a low fit model, while the one used in CFA was determined to reflect an acceptable fit model. However, the data set used in the structural regression model reflected a good fit. In this way, it was believed that it would be possible to find an answer to the question of whether the differences in the fit indexes obtained through LISREL and AMOS were affected by the fit level of the model analyzed. Each of the three data sets used in the study satisfy the normality assumption. Hence, data sets were analyzed by maximum likelihood method in both software packages.

\section{Results and Discussion}

Based on the results of analysis performed on the model with lower fit; it was determined that the difference of fit indices between two software packages did not exceed 0.01 criterion (Cheung \& Rensvold, 2002; Hox, 1995) for none of the fit indices when the results of LISREL and AMOS were compared in terms of GFI, AGFI, RMSEA, SRMR, PNFI, PGFI and ECVI indices. The criterion was set to 0.01 value based upon the studies by Hox (1995) and Cheung and Rensvold (2002) proposing 0.01 value as the measurement invariance criterion. For $\chi^{2} / \mathrm{sd}, \mathrm{CFI}, \mathrm{NFI}, \mathrm{NNFI} / \mathrm{TLI}, \mathrm{RFI}, \mathrm{IFI}, \mathrm{RMR}$ indices; the difference between results by LISREL and AMOS software packages was detected to exceed 0.01 criterion. However, it was observed that the difference of fit indices by LISREL and AMOS packages does not exceed 0.01 criterion when rounding to three decimal places is performed 
on CFI, NFI, IFI fit indices. In addition, the difference of results by two software packages can be neglected when it is considered that there exists no acceptable interval or a constant interval that could be regarded as perfect fit criterion for AIC, CAIC and ECVI fit indices and these fit indices can take higher values unlike other fit indices taking values between 0 and 1 . Therefore, it can be stated that the difference of fit indices by two software packages is significant especially for $\chi^{2} / s d$, NNFI (TLI) and RFI fit indices.

In the model with acceptable fit, it was seen that the difference of fit indices by two programs does not exceed .01 criterion (Cheung \& Rensvold, 2002; Hox, 1995) when results of AMOS and LISREL programs were compared for GFI, AGFI, CFI, NFI, NNFI (TLI), IFI, RMSEA, RMR, SRMR, PNFI and PGFI indices. It was detected that the difference of fit indices by LISREL and AMOS programs exceeds .01 criterion for $\chi^{2} / \mathrm{sd}$, RFI, AIC, CAIC and ECVI indices. On the other hand, the difference of results by two software packages for AIC, CAIC and ECVI indices could be neglected since it is known that there exists no acceptable interval or a constant interval that could be regarded as perfect fit criterion for AIC, CAIC and ECVI fit indices and these fit indices can take higher values unlike other fit indices taking values between 0 and 1 . Thus, it can be stated that the difference of fit indices by two software packages is significant especially for $\chi^{2} / \mathrm{sd}$ and RFI fit indices.

In the model having perfect fit with data set, it was observed that the difference of fit indices by two programs does not exceed .01 criterion (Cheung \& Rensvold, 2002; Hox, 1995) when results of AMOS and LISREL programs were compared for $\chi^{2} / \mathrm{sd}$, GFI, AGFI, CFI, RMSEA, RMR, SRMR, NNFI/TLI, IFI PGFI and ECVI indices. The differences of results by LISREL and AMOS programs for NFI, RFI and CAIC indices are .013, .022 and .014 , respectively. The .01 criterion was exceeded for these indices. However, it was seen that the difference of fit indices by LISREL and AMOS packages exceeds .01 criterion only for RFI index when rounding to three decimal places is performed on NFI, RFI and CAIC fit indices.

The findings of this study suggested that the differences of fit indices calculated by LISREL and AMOS programs are higher in the model with lower fit. Especially, it was observed that for $\chi^{2} / \mathrm{sd}$, which is the first fit index to be examined for detecting the fitness of the model, the difference of fit indices by two programs increased as the fitness of the model decreased. Besides, it was detected that RFI index exceeds .01 criterion in all of three models with perfect, acceptable and lower fit. Nevertheless, the difference of this fit index by two programs was greater in the model with lower fit. One of the fit indices that exceeded .01 criterion in the model with lower fit was NNFI (TLI). The difference of NNFI index by LISREL and AMOS programs was observed to increase as fitness of models decreased. These results indicate that the differences in the fit indexes reported by

LISREL and AMOS are affected by the fit level of the model. Accordingly, it can be put forward that the findings obtained through the studies in which the fit level between the model and data is high and the same hypotheses are tested but different SEM software packages are used can be compared independently of the software packages used. On the other hand, the effect of the SEM software package on the fit indexes obtained should not be ignored in the studies in which the same problem is investigated, different SEM software packages are used, and the goodness of fit is not high. 